\title{
THE PROBLEMS IN PAYBACK OF VALUE-ADDED-TAXES IN TURKEY AND SOLUTIONS ${ }^{1}$
}

\author{
DOI: 10.17261/Pressacademia.2019.1101 \\ PAP- V.9-2019(48)-p.257-261
}

\section{Servet Belge ${ }^{1}$, Levent Polat ${ }^{2}$}

${ }^{1}$ Ministry of Treasury and Public Finance, Istanbul Turkey. servetbelge@hotmail.com, ORCID: 0000-0001-8440-7534

${ }^{2}$ Işık Universty, Maslak Campus, Istanbul, Turkey.

levent.polat@isikun.edu.tr, ORCID: 0000-0002-0072-7651

\section{To cite this document}

Belge S., Polat, L.,(2019). The problems in payback of value-added-taxes in Turkey ans solutions. PressAcademia Procedia (PAP), V.9, p.257261

Permemant link to this document: $\mathrm{http} / / /$ doi.org/10.17261/Pressacademia.2019.1101

Copyright: Published by PressAcademia and limited licenced re-use rights only.

\begin{abstract}
Purpose- The main purpose of this study is related to the problems of payback of value added taxes in Turkey and refund process by determining how the exsting system Works and what could be done to maintain the system.

Methodology- In order to achieve this aim, data are obtained by conducting a survey on tax inspectors, certified public accountants, public accountants, tax office employees involving the value added tax payback process in Istanbul. A total of 62 questionnaires are taken into consideration and analyzes are presented.

Findings- A descriptive framework is emplyed, pie charts and frequency distributions of variables are presented. The results are interpreted by considering the answers of the participants.

Conclusion- As a result of the analysis, some solutions are suggested regarding what needs to be done in order to solve the problems in the value added taxes payback process.
\end{abstract}

Keywords: Value added taxes, VAT exemption, VAT payback process, VAT payback methods.

JEL Codes: H25, H22, M42

\section{TÜRKIYE'DE KDV IADE SÜRECINE ILIŞSKIN YAŞANILAN SORUNLAR VE ÇÖZÜM ÖNERILERI}

\section{ÖZET}

Amaç- Bu çalışmanın temel amacı, Türkiye'de KDV iade sürecine ilişkin yaşanılan sorunların neler olduğunun tespit edilerek bu sorunlara ilişkin ne gibi çözüm önerileri sunulması gerektiğini ortaya koymaktır.

Yöntem- Bu amaca ulaşmak için, İstanbul ilinde Katma Değer Vergisi İade Süreci içerisinde yer alan Vergi Müfettişleri, Yeminli Mali Müşavirler, Serbest Muhasebeci Mali Müşavirler, Vergi Dairesi Çalışanları ile anket çalışması yapılmak suretiyle veriler elde edilmiştir. Toplam 62 anket dikkate alınarak analizler gerçekleştirilmiştir.

Bulgular- Tümevarım metodunun kullanılmakta olduğu araştırmamızda, tanımlayıı bir çerçeve belirlendiğinden, değişkenlere ait pasta grafikleri ile frekans dağılımlarından faydalanılarak katılımcıların sorulara verdikleri cevaplar dikkate alınarak sonuçlar yorumlanmıştır.

Sonuç- Yapılan analizler sonucunda, Katma Değer Vergisi iade sürecine ilişkin tespit edilen sorunların çözümüne ilişkin neler yapılması gerektiğine ilişkin çözüm önerilerine yer verilmiştir.

Anahtar Kelimeler: Katma değer vergisi, KDV istisnası, KDV iade süreci, KDV iade yöntemleri.

JEL Kodları: H25, H22, M42

\footnotetext{
${ }^{1}$ Bu çalışma “Türkiye'de KDV İade Sürecine Illişkin Yaşanılan Sorunlar ve Çözüm Önerileri” isimli yüksek lisans tezinden üretilmiştir.
} 


\section{GíRiş}

Katma Değer Vergisi bir ürün veya hizmetin imal edilip tüketilmesine kadar geçen her aşamada o ürüne veya hizmete katılan değer üzerinden alınan, her aşamada matrahı o ürün veya hizmete ilave edilen katma değer olan, söz konusu ürün veya hizmeti teslim alanın teslim edene ödediği bir tür yayılı muamele vergisidir.

Katma Değer Vergisi'nin indirim mekanizmasına bağlı olma niteliğinden dolayı, her aşamada hesaplanan Katma Değer Vergisi, bir önceki aşamada hesap edilen vergiden indirilmekte ve kalan vergi, mükellef tarafından vergi dairesine yatırılmaktadır. Buna ilişkin 3065 sayılı Katma Değer Vergisi Kanunu'nun 29. maddesinde yapılan düzenleme ile mükellefler tarafından hesaplanan Katma Değer Vergisi'nden, mükelleflerin faaliyetlerine ilişkin olarak yapmış oldukları alışlar içerisinde yer alan Katma Değer Vergisi indirilmekte kalan tutar, mükellefin Katma Değer Vergisi yönünden bağlı olduğu vergi dairesine ödenmektedir. Eğer mükellef tarafından ödenen Katma Değer Vergisi, mükellef tarafından yüklenilmiş olan Katma Değer Vergisi tutarından daha az ise, fark sonraki döneme devretmekte ve mükellefe iade edilmemektedir. Ancak Katma Değer Vergisi Kanunu’nda yer alan bir takım işlemler sebebiyle mükellefler tarafından yüklenilmiş olan Katma Değer Vergileri belirli şartlar ile mükellefin talep etmesi halinde iade edilebilmektedir. Bu işlemleri Tam istisna kapsamında olanlar, indirimli orana tabi olanlar, tevkifat kapsamında olanlar ve fazla ve yersiz ödemeler olarak 4 temel başlık altında toplamak mümkündür.

Uygulamada iade yöntemleri nakden ve mahsuben iade olmak üzere 2 gruba ayrılmakta olup; iadeler, türü, tutarı ve içeriğine göre farklı süreçlerle mükellefler tarafından talep edilebilmektedir. Mükellefler; teminatsız ve incelemesiz iade limitinin altında yer alan iade talepleri, Teminat karşılığı iade talepleri, Yeminli Mali Müşavirler tarafından düzenlenen Katma Değer Vergisi iadesi tam tasdik raporu kapsamındaki iade talepleri ile Vergi İnceleme Raporu kapsamındaki iade taleplerine göre farklı süreçlerle iadelerini alabilmektedirler.

Katma Değer Vergisi iade sistemi mükellefler ve devlet açısından oldukça önemlidir. Bu sistem ile mükelleflerin gerçekleştirmiş olduğu bir takım işlemler içerisinde yer alan Katma Değer Vergisi, mevzuatta yer alan şartlara bağlı olarak mükelleflere iade edilmektedir. İadesi gereken bu Katma Değer Vergisi, bir bakıma mükellefler tarafından devlete verilmiş olan borç olarak görülebilir. Belirtilen bu borç paranın mükelleflere iade edilmesi ne kadar uzarsa, mükelleflerin de kullanabilecekleri likitide imkanı da bir o kadar kısıtlı olacaktır. Bunun sonucunda mükellefler tarafından yapılacak olan üretim ve hizmetler tehlikeye düşebilecek ve mükelleflerin rekabet gücü azalabilecektir. Devlet açısından Katma Değer Vergisi iadesi likitidenin ekonomiye tekrar sokularak parasal genişlemenin sağlanması açısından önemlidir. Bu sebeplerle Katma Değer Vergisi iade sistemi ve sürecinin etkinliği hem mükellefler hem de devlet açısından önem arz etmektedir.

\section{LITERATÜR INCELEMESI}

Katma değer vergisi(KDV) bir ürün veya hizmetin imal edilip tüketilmesine kadar geçen her aşamada o ürüne veya hizmete katılan değer üzerinden alınan, her aşamada matrahı o ürün veya hizmete ilave edilen katma değer olan, söz konusu ürün veya hizmeti teslim alanın teslim edene ödediği bir tür yayılı muamele vergisidir (Bilici, 2015).

KDV Kanununun 29. Maddesinde Vergi indirimi müessesesi düzenlenmiş olup hesaplanan vergiden indirilecek KDV'lerin neler olduğu belirtilmiş, 32. Maddesinde ise KDV'den istisna edilmiş işlemlere ilişkin KDV indiriminin nasıl gerçekleştirileceğine dair detaylara yer verilmiştir.

KDV kanununa göre yüklenilmiş olan KDV'ler mükellef tarafından indirim yolu ile giderilebilir, mükellef indirim yolunu tercih etmez ise iade mekanizması ile iade talebinde bulunabilir veyahut yüklenilmiş bulunan KDV indirim veya iade konusu olmayacak nitelikte ise bu durumda mükellef gider yazabilir ya da maliyetlerine dahil edebilir.

İadeler nakden veya mahsuben talep edilebilmektedir. Nakden iade şartları mahsuben iadelere istinaden daha katıdır. Çoğunlukla mahsuben iadeler teminat veya inceleme raporuna gerek görülmeden yerine getirilmektedir. Bu husus mahsuben iadeleri nakden iadeye nazaran tercih edilebilir yapmaktadır (Vural,2015). KDV Genel Uygulama Tebliği'nde, mükellefler tarafından yapılan KDV iade taleplerinin aşağıda yer alan usuller ile yerine getirilmesi esası benimsenmiştir. Bu usuller:

-YMM KDV iadesi tasdik raporu ibraz edilmesi,

-Teminat gösterilmesi,

-Vergi inceleme raporu düzenlenmesi,

-YMM raporu, teminat veya ViR aranmaksızın yalnızca iade için aranılan belgelerin tamamlanması, olarak belirtilebilir (Avcı,2015).

Ülkemizde KDV iade uygulaması KDV'nin yürürlüğe girmesinden sonra uygulamaya konulan istisna ve muafiyetlerle önemli bir alan olmaya başlamış ve istisna ve muafiyetlerin genişlemesine bağlı olarak KDV iadesinin uygulama alanı da genişlemiştir. Bu durum mükellefler tarafından KDV iade taleplerinin artmasını da beraberinde getirmiş olup bu artan talepler orantılı olarak, talep edilen KDV'nin türüne ve içeriğine göre farklı iade yöntem ve süreçleri uygulamada kendine yer bulmuştur.

\section{YÖNTEM}

Bu araştırma durum tespiti yapılmasını sağlamaya dayalı tanımlayıcı bir çalışmadır. Tanımlayıcı araştırma modeli, sorun ve sorun ile ilişkili durumları ve değişkenler arasındaki bağları tanımlayarak geleceğe dair tahminler yapabilmektir. Bu çalışma da nitel araştırma tekniğinden faydalanılmıştır. Nitel araştırma "gözlem, görüşme ve doküman analizi gibi nitel veri toplama yöntemlerinin kullanıldığı, algıların ve olayların doğal ortamda gerçekçi ve bütüncül bir biçimde ortaya konmasına yönelik bir sürecin izlendiği araştırma türüdür." (Arslan,2012). Türkiye'de KDV iade sürecine ilişkin yaşanılan sorunlar ve çözüm önerilerine ilişkin çalışma da, daha faydalı olacağı düşünüldüğünden veri toplama aracı olarak anket yöntemi seçilmiştir. İlgili anketin oluşturulması sırasında bu alanda yapılmış çeşitli akademik çalışmalar ve muhtelif kaynaklardan 
faydalanılmıştır. Anket formunda yer alan soruların açık, anlaşılır olmasına ve herhangi bir yönlendirmeye mahal vermemesine özen gösterilmiştir.

Türkiye'de KDV iade sürecine ilişkin yaşanılan sorunlara ilişkin anket formumuz 2 ayrı bölüm ve toplamda 29 sorudan oluşmaktadır. İlk bölüm, KDV İade sürecine ilişkin katılımcıların görüşleri hakkında bilgilerin yer aldığı 25 sorudan oluşmaktadır. İkinci bölüm ise katılımcılar hakkında genel bilgilerin yer aldığı( Meslek, Kıdem, Öğrenim Durumu, Yaş) 4 sorudan oluşmaktadır.

Bu çalışma için 31 Vergi Müfettişi, 18 Yeminli Mali Müşavir ve SMMM, 13 Vergi Dairesi Çalışanı yargısal örnekleme yöntemi ile mesleği, kıdemi, yaşı ve öğrenim durumu dikkate alınarak seçilmiştir. Anketin uygulanması anket formlarının ilgili katılımcılar ile yüz yüze görüşülmek suretiyle cevaplandırılması şeklinde olmuştur.

Bu araştırmamızda olasılıksız örnekleme yöntemleri içerisinde yer alan " Yargısal Örnekleme Yöntemi" kullanılmıştır. Yargısal örnekleme araştırmanın amaçları doğrultusunda evrenin soruna en uygun olan belirli bir bölümünü gözlem konusu yapmak demektir.

Çalışmamızın örnek kitlesini ise İstanbul ilinde KDV iade süreci içerisinde yer alan ve süreçte bilfiil aktif olarak bulunan ve yargısal örnekleme yöntemi ile seçilen Vergi Müfettişleri, Yeminli Mali Müşavirler, SMMM, Vergi Dairesi Çalışanları oluşturmaktadır. Çalışma verilerinin güvenilirliği ve doğru sonuçlara ulaşabilmek amacıyla mesleki deneyimi 5 yıl ve daha fazla olan katılımcılar ile anket düzenlenmiş olup, mesleki deneyimi 5 yıldan daha az olan katılımcılar tercih edilmemiştir.

Dolaylı vergiler kişilerin her türlü tüketim mallarına uygulanan, satıcısından veya üreticisinden alınan, fiyatlara eklenerek nihai tüketiciye yansıtılan vergilerdir. Bu vergiler; yansıtılabilmesi, fiyatların içine gizlenebilmesi ve peşin olarak tahsil edilebilmesi gibi sebeplerden ötürü sıkça tercih edilirler. Dolaylı vergiler sadece yurt içindeki ticari işlemlerden değil, yurt dışındaki ticari işlemlerden de alınır. Buna göre dolaylı vergileri; dâhilde alınan vergiler, dış ticaretten alınan vergiler ve diğer vergi türleri olarak ayırmak mümkündür.

\section{BULGULAR}

Katılımcılar ile yapılan anket çalışması neticesinde ilgili anketlere verilen cevaplar dikkate alındığında aşağıda yer verilen sorunlar tespit edilmiştir.

İhraç Kayıtlı mal satan firmalar satış bedeli üzerinden hesapladıkları ancak alıcıdan tahsil edemedikleri KDV'ni iade olarak talep edebilmektedirler. Bu uygulamanın İmalatçı-ihracatçı firmalarda da uygulanmamakta olması iade sürecini olumsuz etkilemektedir.

KDV İadesi Ön Kontrol Raporuna Dayalı İade Uygulaması,iTUS,HiS ve Artırımlı teminat uygulaması şartları kendilerinden beklenen sonuçları vermemiştir.

KDV'nin hesaplanmasına ilişkin"maliyet esasına" dayalı uygulama benimsenmiş iken KDVGUT ile bu uygulama terk edilerek, "liste veya belge esası”" yönteme geçilmiş olması doğru ve gerçekçi bulunmamaktadır.

Teminatsız ve incelemesiz iade limiti yeterli değildir.

Mahsuben iade kapsamı genişletilmelidir.

KDV iade incelemelerinin hızlanmasına ilişkin oluşturulan KDV iade inceleme ekipleri,ihtisas vergi daireleri kuruluş amaçlarını yerine getirme konusunda yetersiz kalmıştır.

KDV iade süreci içerisinde yer alan personel nicel ve nitel anlamda yeterli bulunmamakta olup sistem altyapısı yetersizdir.

YMM'ler tarafından düzenlenen raporlar her vergi dairesinde farklı işleme tabi tutulmakta,YMM'lerde GiB bilgi bankasına ulaşım mümkün olmamakta, YMM karşıt incelemelerinde sorunlar yaşanmaktadır.

\section{SONUÇ VE ÖNERILER}

KDV iade sürecine ilişkin yaşanılan sorunların tespitine yönelik katılımcılar nezdinde yapılan anket çalışması neticesinde elde edilen sonuçların değerlendirilmesi sonucunda aşağıda yer verilen sonuç ve önerilere ulaşılmıştır. Satış bedeli üzerinden hesaplanan ve alıcıdan tahsil edilemeyen KDV 'nin iade olarak talep edilebilmesine ilişkin uygulamanın imalatçı-ihracatçı firmalara da uygulanması gerekir. His, iTUS, KDV İadesi Ön Kontrol Raporuna Dayalı İade Uygulaması, Artırımlı Teminat Uygulamasının daha etkin ve verimli olabilmesi ve genele yayılabilmesi için için katı olan şartları mükellefler lehine esnetilecek bir takım düzenlemeler gereklidir.

İadesi gereken KDV'nin hesaplanmasına ilişkin liste veya belge esaslı yöntem yerine, maliyet esaslı yönteme geçilmelidir. Teminatsız ve incelemesiz iade limiti artırılmalıdır. Mahsuben iade kapsamı genişletilmelidir.

Oluşturulmuş olan birimler(İhtisas Vergi Daireleri, lade inceleme Ekipleri) ve kurulması planlanan KDV İade Grup Başkanlığı iade incelemelerinin daha hızlı şekilde sonuçlanması için öncelikle personel nitelik ve sayılarının artırılması gerekmekte, oluşturulacak olan gruplarda iade türleri itibariyle ihtisaslaşmanın artırılması amacıyla işbölümünün geliştirilmesi, iadeye ilişkin mevzuatın sadeleştirilmesi gerekmektedir.

KDV iade taleplerine ilişkin bilgi alış verişi konusunda otomasyon üzerinden yeterli entegrasyonun sağlanması gerekmektedir. Vergi daireleri tarafından KDV iade sürecinde istenilen bilgi ve belge taleplerine ilişkin uygulama standardı getirilmeli ve sınırları net bir şekilde çizilmelidir.

YMM'ler tarafından düzenlenecek KDV iadesi tasdik raporlarında yüklenilen KDV listesinde yer alan mükelleflerin \%80' ine karşıt yapma zorunluluğunun esnetilebildiği istisnai durumlar getirilmek suretiyle sürecin tıkanmasının önüne geçilebilir. Vergi mahremiyetini ihlal etmeyecek şekilde GiB bilgi bankasına YMM'ler tarafından ulaşılabilmesine imkan verilmesinin iade sürecine olumlu katkı sağlayacaktır. 
YMM'ler tarafından düzenlenen raporların her vergi dairesinde farklı işlemlere tabi tutulmaması ve ilgili raporlara şüpheyle bakılmaması açısından uygulama birliğini sağlamaya yönelik düzenlemeler yapılmalıdır.

KDVIRA programının 4 alt satıcıya kadar denetim yaparak, 4. Alt kademedeki satıcıda tespit etmiş olduğu bir hukuka aykırılıktan dolayı iade talep eden mükellefte iade kısıtlaması ve sınırlandırmasına gitmesi uygulamada sorunlar yaratmakta olduğu için iade sürecinin tıkanmasına ve işlemez duruma gelmesine yol açan bu uygulama tekrar gözden geçirilmeli ve gerekli düzeltmeler yapılmalıdır.

\section{KAYNAKÇA}

Arslan Metin(2012). “Araştırma Yöntem ve Teknikleri” Harran Üniversitesi Birecik Meslek Yüksek Okulu,

Avcı Ö.(2015). “ Bilinen ve Bilinmeyenleriyle ITUS” Vergi Dünyası Dergisi, Sayı:410,

Bilici N. (2015). "Türk Vergi Sistemi”, Savaş Yayınevi, Ankara,

Vural M.(2015). “ KDV İade Rehberi” Maliye Bakanlığı Hesap Uzmanları Derneği Yayınları, İstanbul,

213 Sayılı Vergi Usul Kanunu

3483 sayılı Muamele Vergisi Kanunu

3065 sayılı Katma Değer Vergisi Kanunu

01/06/1989 tarih ve 20194 sayılı Resmi Gazete' de yayımlanan "Serbest Muhasebecilik, Serbest Muhasebeci Mali Müşavirlik ve Yeminli Mali Müşavirlik Kanunu"

6183 sayılı Amme Alacaklarının Tahsil Usulü Hakkında Kanun

Katma Değer Vergisi Kanunu Genel Gerekçesi Kanun Tasarısı ve Komisyon Raporları

02.01.1990 tarih ve 20390 sayılı Resmi Gazete’ de yayımlanan “Yeminli Mali Müşavirlerin Tasdik Edecekleri Belgeler, Tasdik Konuları, Tasdike İlişkin Usul ve Esaslar Hakkında Yönetmelik"

Katma Değer Vergisi Uygulama Genel Tebliği

20 Seri No'lu SM, SMMM ve YMM Kanunu Genel Tebliği

22 seri numaralı KDV Genel Tebliğinde Değişiklik Yapılmasına Dair Tebliğ

27 Seri No'lu SM, SMMM ve YMM Kanunu Genel Tebliği

29 Seri No.lu SM, SMMM, YMM Kanunu Genel Tebliği

34 Seri No.lu SM, SMMM, YMM Kanunu Genel Tebliği

37 Seri No.lu SM, SMMM, YMM Kanunu Genel Tebliği

20 Seri No.lu SM, SMMM, YMM Kanunu Genel Tebliğ

Maliye Bakanlığı'nın 24.02.2010 Tarih ve 53/5373-163/14775 Sayılı 2010/1 Sıra No.lu KDV iç Genelgesi

Bursa Vergi Dairesi Başkanlığının 07.04.2014 tarih ve 45404237-130[I-13-95]-96 sayılı özelgesi

İzmir Vergi Dairesi Başkanlığının 30.11.2005 tarih ve GiB.4.35.17.01.KDV.02.4821/679 sayılı muktezası

Kocaeli Vergi Dairesi Başkanlığının 16.04.2012 tarih ve GïB.4.41.15.01-130[8-2012/7]-96 sayılı muktezası

Maliye Bakanlığının 04.07.2001 tarih ve 32/3224-2428/36020 sayılı muktezası

Maliye Bakanlığı'nın 16.07.2003 tarih ve 54/5429-687/30924 sayılı muktezas

Maliye Bakanlığı'nın 27.06.1996 tarih ve 55/5532-493/29039 sayılı muktezası

Maliye Bakanlığı'nın 08.01.2003 tarih ve 53/5332-559/839 sayılı muktezası

Maliye Bakanlığının 29.11.1988 tarih ve 32/3204-687/16359 sayılı muktezası

Maliye Bakanlığı'nın 11.06.1993 tarih ve 79/11-1359/36289 sayılı muktezası

Maliye Bakanlığı'nın 19.11.2003 tarih ve 55/5529-694/49876 sayılı muktezası

Danıştay 7. Dairesinin 19.11.1991 tarih ve E:1991/2116, K:1991/2759 sayılı kararı

Danıştay 7. Dairesinin 3004.1991 tarih ve E:1991/435 ve K:1991/1589 sayılı kararı 
Danıştay 9. Dairesinin 18.03.2008 tarih ve E:2006/3306, K:2008/1365 sayılı kararı Danıştay 9. Dairesinin 26.04.2012 tarih ve E:2009/81, K: 2012/2005 sayılı kararı Danıştay VDDK'nın 19.06.2013 tarih ve E:2011/359, K:2013/359 sayılı kararı http://www.ozdogrular.com/v1/content/view/13681/ 